January 2017

\title{
E-Journals and the Big Deal: A Review of the Literature
}

Cindy Sjoberg

San Jose State University, sjobergcindy@gmail.com

Follow this and additional works at: https://scholarworks.sjsu.edu/ischoolsrj

Part of the Collection Development and Management Commons, Scholarly Communication Commons, and the Scholarly Publishing Commons

\section{Recommended Citation}

Sjoberg, C. (2017). E-Journals and the Big Deal: A Review of the Literature. School of Information Student Research Journal, 6(2). https://doi.org/10.31979/2575-2499.060203 Retrieved from https://scholarworks.sjsu.edu/ischoolsrj/vol6/iss2/3

This article is brought to you by the open access Journals at SJSU ScholarWorks. It has been accepted for inclusion in School of Information Student Research Journal by an authorized administrator of SJSU ScholarWorks. For more information, please contact scholarworks@sjsu.edu. 


\title{
E-Journals and the Big Deal: A Review of the Literature
}

\begin{abstract}
Faced with shrinking budgets and increased subscription prices, many academic libraries are seeking ways to reduce the cost of e-journal access. A common target for cuts is the "Big Deal," or large bundled subscription model, a term coined by Kenneth Frazier in a 2001 paper criticizing the effects of the Big Deal on the academic community. The purpose of this literature review is to examine issues related to reducing e-journal costs, including criteria for subscription retention or cancellation, decision-making strategies, impacts of cancellations, and other options for e-journal content provision. Commonly used criteria for decision-making include usage statistics, overlap analysis, and input from subject specialists. The most commonly used strategy for guiding the process and aggregating data is the rubric or decision grid. While the e-journal landscape supports several access models, such as Pay-Per-View, cloud access, and interlibrary loan, the Big Deal continues to dominate. Trends over the past several years point to dwindling support for the Big Deal however, due largely to significant annual rate increases and loss of content control.
\end{abstract}

\section{Keywords}

e-journals, Big Deals, overlap analysis, decision grid, Pay-Per-View, interlibrary loan

\section{About Author}

Cindy Sjoberg, School of Information, San José State University.

Correspondence concerning this proposal should be addressed to Cindy Sjoberg, School of Information, One Washington Square, San José, CA 95192. Email: sjobergcindy@gmail.com 
The past fifteen years have seen a dramatic shift in the scholarly journals landscape. As libraries shed print subscriptions in favor of electronic-only access, issues of content provision and ballooning costs have become forefront in the literature. In particular, the large package subscription model, or Big Deal, has featured prominently, as libraries struggle to balance providing the highest-quality resources with the reality of rising costs and stagnant or declining collection budgets.

Libraries across North America and beyond are facing significant pressures to re- examine serials subscriptions. While libraries demonstrate a high degree of motivation in the literature to provide resources that meet the needs of their users, many find themselves facing the same challenges: large, inflationary price increases, decreasing budgets, and fluctuating exchange rates creating budget uncertainties (Bosch \& Henderson, 2015). In particular, libraries are increasingly evaluating their Big Deal subscriptions in an effort to curb costs. The purpose of this literature review is to examine issues related to reducing e-journal costs, including criteria for subscription retention or cancellation, decision-making strategies, impacts of cancellations, and other options for e-journal content provision.

\section{What's the Big Deal?}

According to a study by Bergstrom, Courant, McAfee, and Williams (2014), the majority of North American libraries have subscribed to bundled contracts with large commercial journal publishers. Bergstrom et al. defined the Big Deal as "contracts for bundled access to a publisher's entire journal list" (p. 9426) and ascribed the origin of the term to Frazier's 2001 article, "The Librarians' Dilemma: Contemplating the Costs of the 'Big Deal."' By 2001, Big Deals were becoming a fixture of the journal publication landscape; they originated in 1996 when Academic Publishing (AP) negotiated a three-year license with the U.K.'s Higher Education Funding Council for access to all 200 titles in the AP collection (Poynder, 2011). Frazier (2001) argued strongly against entering into bundled subscription contracts, using game theory to make the point that libraries acting in self-interest do not support the greater good of scholarly communication. Frazier predicted that this model would create indispensability of these products, allow large commercial publishers to control pricing, shift work traditionally done by serials vendors to library staff, and increase libraries' vulnerability to content changes.

Although Frazier conceded in a 2005 follow-up article that Big Deals could prove beneficial to smaller institutions, a review of the current e-journal landscape reveals a shift away from Big Deals. The 2014 EBSCO Budgeting and Trends Survey indicated that $57 \%$ of respondents would consider breaking up their Big Deal packages for subscriptions to individual titles, $77 \%$ plan to renegotiate pricing, and $74 \%$ of publishers plan to offer smaller packages (as cited in Bosch \& Henderson, 2015). Participants in a 2006 panel session, "Serials Industry: Truth or Dare," expressed a preference for using multiple vendors rather than "putting their eggs in one basket," (Schoen et. al, 2006, p. 141) as they felt it granted them greater bargaining leverage.

The significant and rising cost of Big Deal packages is a primary 
contributing factor in libraries' decisions to reevaluate e-journal subscriptions. Historically, the Big Deal subscription fee was based on the institution's prior print subscription cost (Poynder, 2011). Publishers would add an electronic premium of between 5 and 11 percent and build in inflationary increases of $6 \%$ per year (Rowse, as cited in Poynder, 2011). This inflationary increase has prevailed in the market since the introduction of Big Deals (Bergstrom, Courant, McAfee, \& Williams, 2014, p. 9426), with more than 3,000 e-journal packages offered by EBSCO in 2014 reflecting an average annual price increase of 6.6\% (Bosch \& Henderson, 2015, p. $31)$.

\section{Breaking Up is Hard to Do}

The focus of many articles published between 2005 and 2015 is the discussion of factors and strategies used to evaluate Big Deal subscriptions and the serials collection in general. For the purposes of this paper, factors are the objective and subjective data collected by each library to inform cancellation and renewal decisions. Strategies are the methods by which the factors are applied to the decision-making process. Libraries use several common factors when evaluating ejournals. These include pricing and inflation, usage statistics, cost per use, overlap analysis, and input from subject specialists.

\section{Usage Statistics and Cost per Use}

Usage statistics and cost per use are among the most often cited factors used to evaluate e-journals (Banks, 2006; Chilton \& Zhao, 2012; Dawson, 2015; Enoch \& Harker, 2015; Suseela, 2011; Sutton, 2013). Bucknall, Bernhardt, and Johnson (2014) analyzed cost per use data for deals with seven publishers with whom the Carolina Consortium held subscriptions in excess cost of $\$ 250,000$ per year. They examined the data on three levels: deal level, school level, and title level. Their results identified seven schools in the consortium with packages demonstrating high cost per use. After balancing cost per use with a list of additional criteria, such as departmental needs and comparisons of package versus stand-alone pricing, three schools chose to cancel. Bucknall et al. (2014) stressed that cost per use alone is insufficient for determining cancellation decisions.

Jones, Marshall, and Purtee (2013) echoed this sentiment in a case study report from their own institution. Facing a major budget shortfall at Mississippi State University Library and a short timeline to deliver the necessary cutbacks, the authors reported basing cancellation decisions solely on usage statistics and cost per use data. The impact was substantial. Mississippi State University Library lost current access to over 2,800 journals; many disciplines with fewer faculty and students, especially in the Social Sciences, lost all of their titles previously available from the cancelled packages. To help mitigate negative impacts in the future, the authors outlined a plan to solicit input from faculty, reference librarians, and subject specialists, in addition to analyzing usage statistics and cost per use data.

Bucknell (2012) discussed the fallibility of cost per download data, including the various ways in which these data can be misleading and how the effects can be mediated. Bucknell identified the principle factors contributing to misleading data as user interface (UI) and the extent and type of content being compared. For example, when publishers actively improved their platform UI and 
engaged in marketing to increase the number of downloads, usage statistics increased. UI also affected user behavior when comparing HTML and PDF views, if both types of access were available. Davis and Price (as cited in Bucknell, 2012) found a measurable difference in the ratio of PDF to HTML views depending on the site design of the vendor platform; when a database or link resolver opened an HTML full-text version of an article on the landing page versus an abstract-only view, and the user then downloaded a PDF version, the usage was counted twice.

Bucknell (2012) also identified the amount and currency of available content as important considerations when examining cost per download. For instance, the number of downloads for a journal title with only two years of content cannot be accurately compared to a title with 15 years of content. This comparison unfairly penalizes newer journals and titles with recent subscriptions (i.e. those with no available backfile). Further, usage patterns may vary considerably between disciplines, thereby affecting usage statistics (Bucknell, 2012; Tenopir, 2009). Statistics considered low in one discipline may be considered average or high in another. This is due, in part, to the type of articles users access. Shorter news briefs and reviews may account for a greater percentage of use in some disciplines, compared to longer, more in-depth research papers used in others.

Counting Online Usage of NeTworked Electronic Resources (COUNTER) is a non-profit standards organization mandated with overseeing consistent usage reporting. It has developed a Code of Practice that has become the standard for counting the use of electronic resources (COUNTER, 2016). While COUNTERcompliant usage statistics are a positive development for the evaluation of electronic resource usage, Tenopir (2009) posited that these statistics alone provided little proof of actually fulfilling the information needs of the user. In other words, usage statistics do not indicate the value or satisfaction of the accessed information to the user, the user's purpose for accessing the information, or the impact of that information.

\section{Overlap Analysis}

Many libraries employed overlap analysis as a decision-making factor when evaluating journal subscriptions (Banks, 2006; Enoch \& Harker, 2015; Sutton, 2013; Trail, Chang-FitzGibbon, \& Wishnetsky, 2012). Overlap analysis is a comparison of current journal holdings to determine any duplication of titles. Many libraries described in the literature compared the content of Big Deal subscriptions with other electronic serials holdings. Trail et al. (2012) compared electronic to print holdings only (thereby factoring in the issue of bindery costs). Enoch and Harker (2015) compared Big Deal subscriptions with both electronic and print holdings. None of these authors used overlap analysis as the only factor; often it was one in a range of factors that included costs, usage statistics, input from specialists, and others. Banks (2006) also pointed to the importance of examining the specific years of coverage for overlapping journal titles, as matching titles did not necessarily equate to matching coverage.

Overlap analysis generally lead the authors to a further examination of the unique titles; specifically whether these titles were available through other current subscription packages (Banks, 2006; Sutton, 2013). In Banks' 2006 analysis of 
Wilson Social Sciences Abstracts (Wilson SSA), researchers found that nearly $85 \%$ of the journals indexed and abstracted by Wilson SSA were also available in two or more of the four comparison databases, and that $100 \%$ of the unique titles were available from other databases not included in the initial comparison. Sutton (2013) described analyzing the unique titles identified through overlap analysis by both quantity and quality. While the quantity of unique titles is an important factor when considering cancellations, it becomes a moot point if the titles are of little use or low quality. Sutton's study used quality indicators such as lists of recommended resources compiled by discipline-specific professional organizations or Ulrich's Periodicals Directory, journals in which faculty publish, course reserve requests and recommendations from faculty, and citations from the institution's graduate theses and dissertations.

\section{Subject Specialists}

Input from faculty, liaison librarians, and other subject specialists played into the e-journal decision process for many libraries (Chilton \& Zhao, 2012; Dawson, 2015; Enoch \& Harker, 2015). Some researchers created formal rubrics or decision grids and asked subject specialists to fill them in (Blackburn, McFarland, \& Reed, 2013; Chilton \& Zhao, 2012; Enoch \& Harker, 2015; Foudy \& McManus, 2005). Chilton and Zhao (2012) developed a decision grid, asking subject librarians to rate criteria such as ease of access, breadth and audience, uniqueness of content and support for curriculum, alternative or similar resources, and frequency of use. Enoch and Harker (2015) asked faculty and librarians to rank journal titles in their subject area, as well as evaluate interdisciplinary titles. Based on a review of the research, Dawson (2015) concluded that combining multiple methods of evaluation, including soliciting input from subject specialists and other stakeholders, would best support informed cancellation decisions. To that end, Dawson conducted an online survey of faculty, graduate students, staff, and researchers from the University of Saskatchewan's Department of Chemistry regarding a proposed cancellation of the American Chemical Society's Web Editions Big Deal bundle. Dawson asked survey participants to rate each journal title included in the subscription as "'Essential,' 'Good to have,' or 'Unnecessary' with regards to their own research, teaching, and other professional activities" (“Method 3: User Survey," para. 3).

Researchers gained important feedback from subject specialists to support e-journal cancellation decisions, however the process of gathering and analyzing the information included challenges. Enoch and Harker (2015) found the process of collecting and collating feedback to be problematic; some faculty and librarians found the information too overwhelming, while others devised their own ranking system, forcing the authors to normalize the data before use. Dawson (2015) valued the feedback collected from the survey, but noted that user surveys are unsuitable for rapid analysis. Soliciting input was advantageous when final decisions were made however, as it improved acceptance by faculty and librarians (Enoch \& Harker, 2015). In addition to the buy-in cultivated by collecting feedback from faculty and subject specialist librarians, collection librarians can use these opportunities to build collegial relationships and, as Dawson (2015) pointed out, help create awareness of electronic journal access models and their financial 
impacts. Most importantly, collection librarians can tap into the subject expertise of their colleagues to develop a more extensive and holistic understanding of their users' information needs.

\section{Additional Factors}

While usage statistics, overlap analysis, and input from subject specialists are the most frequently cited factors supporting e-journal cancellation decisions, several others are discussed in the literature. Dawson (2015) and Sutton (2013) employed citation analysis: Dawson examined trends drawn from amalgamating the reference lists of faculty-authored publications, while Sutton studied unique titles identified through an overlap analysis. Suseela (2011) identified citation analysis among twelve important considerations for serials assessment, including availability in alternate formats, core journals coverage, usage, cost per use, language, and price.

Impact factor is a metric that expresses the average number of times a journal's articles were cited over a two-year period, thus indicating the journal's relative value within the discipline. Impact factor was cited in several analyses of e-journal subscriptions (Juznic, 2009; Schöpfel \& Leduc, 2012; Suseela, 2011; Sutton, 2013). Suseela (2011) listed impact factor as one of the important considerations for serials assessment, but did not apply it in this study. Sutton (2013) applied impact factors obtained from Journal Citation Reports as part of the second-tier of the evaluation process. Juznic (2009) further cited impact factor as a common instrument in e-journal evaluation and a good indicator of the quality of scientific journals.

Pareto's Principle, a theory positing that $80 \%$ of events (or uses, in this case) result from $20 \%$ of causes (or journal titles), has been used to determine the strongest and weakest performing journals in a Big Deal package (Dawson, 2015; Enoch \& Harker, 2015; Schöpfel \& Leduc, 2012). These data can be compared to analyses of other Big Deals or established benchmarks. Schöpfel and Leduc (2012) examined e-journal usage patterns to identify whether they reflected Pareto's 80/20 ratio or a variant of the ratio: Anderson's long tail distribution, a statistical principle posting that $80 \%$ of uses result from 30 to 50 percent of journal titles. Their findings indicated that while usage statistics are somewhat reflective of the long tail distribution, the model was ineffective as a prediction tool (Schöpfel \& Leduc, 2012).

Several other factors mentioned in the literature are worth noting. Participants in the panel discussion, "Serials Industry: Truth or Dare" (Schoen et al., 2006) identified factors including the reputation of the publisher or editorial board, interlibrary loan (ILL) requests, and how resources would support academic programs. Banks (2006) employed search retrieval analysis by using controlled subject headings and keyword queries for a sample of four social sciences-related questions and examining the search results, to determine a measure of quality. While no one factor or combination has proven to be most effective in evaluating Big Deal subscriptions, the literature offers valuable insight into the efficacy of a range of options, both quantitative and qualitative. Collection librarians must choose the factors that best suit the context of their analysis, according to the nature

of the subscription in question, available research time, and timeline for the 
decision.

\section{Strategies}

Besides identifying the various factors that informed their decisions regarding ejournal subscriptions, most authors discussed the strategies they employed to choose their data points and analyze the resulting data. The most commonly used strategy was the rubric or decision grid. The decision grid may be used by researchers to weigh criteria or tally scores, or simply as a way to aggregate data in a suitable format for comparison. A decision grid is an effective method of approaching a complex issue involving multiple criteria. Blackburn, McFarland, and Reed (2013) used a 27-point decision grid of quantitative and qualitative factors to evaluate journal subscription packages at Vancouver Island University. Juznic (2009) presented a quantitative decision grid process to determine collection and ejournal funding issued by the Slovenian Research Agency for the approximately 100 research libraries in Slovenia. The process described in Juznic's study produced an important tool to help libraries better match their resources to users' needs, incentivize libraries to create consortia, and design and implement better collection development policies. Dawson's (2015) triangulation model could be considered a variation of the decision grid. It aggregated three distinct types of weighted evaluation data - full-text downloads, citation analysis of faculty publications, and user feedback - to present a holistic view of a Big Deal subscription.

Juznic (2009), Enoch and Harker (2015), and Chilton and Zhao (2012) cited as a model the decision grid process outlined by Foudy and McManus in their 2005 article, "Using a Decision Grid Process to Build Consensus in Electronic Resources Cancellation Decisions." Foudy and McManus described developing the model, based on Bens' book, Facilitation at a Glance!, to create a tool for identifying $25 \%$ of their electronic resources for possible cancellation due to budget shortfalls. Although they ultimately suggested some improvements to the model for future use, Foudy and McManus found the process very successful overall based on the positive feedback they received from faculty. They noted that it was particularly effective in reducing anxiety for decision-makers.

Chilton and Zhao (2012) employed Foudy and McManus' (2005) decision grid process as part of an e-resource management framework built on the Analyze, Design, Develop, Implement, Evaluation (ADDIE) model for instructional design. Chilton and Zhao chose the ADDIE model for e-resource management as a means to systematically analyze users and systems, design and modify services, and evaluate the results - an ongoing process that reflects the "ever-shifting [and] constantly evolving" landscape of e-resources (p. 22). In the ADDIE model, "analyze," refers to understanding users and stakeholders, as well as existing systems and processes for e-resource management. This analysis informs the "design" of improvements to systems and communication. Systems and processes are built during the "develop" stage, and then "implemented." Finally, "evaluation" occurs throughout all stages, and changes are enacted based on user feedback, workflow analysis, and management input. Chilton and Zhao appreciated the ADDIE model, as it provided a framework to help focus their efforts, exposed shortcomings in the system, and enabled them to apply a user-centered and 
evidence-based strategy to their e-resource management.

Sutton (2013) advocated using a two-stage analysis process to determine renewal or cancellation of e-journal subscriptions. The first stage consisted of examining COUNTER usage data and comparing them against baseline data derived from the most frequently used resources. If the results did not indicate a clear decision, the second stage provided more in-depth analysis, including overlap analysis, citation analysis, journal usage, and impact factor (Sutton, 2013). The advantage of Sutton's two-part method was efficiency. The strongest and weakestperforming resources were quickly revealed, and then additional time and effort were applied in further analysis of the remaining subscriptions (Sutton, 2013).

\section{Saying Farewell}

Once libraries make the difficult decision to cancel e-journal subscriptions, what happens next? The process that follows e-journal cancellations is less clearly addressed in the literature. There have been few studies describing how librarians communicate with faculty, negotiate with vendors, or assess the impact of cancellation on users. Authors who described receiving feedback from faculty and subject librarians following cancellations generally reported a positive outcome when those users were involved in the decision-making process (Enoch \& Harker, 2015; Foudy \& McManus, 2005). Fostering communication with faculty, subject librarians, and other stakeholders in advance of cancellations helped to inform users of the situation and allowed for possible input in the decision (Chilton \& Zhao, 2012; Dawson, 2015). It also provided opportunities to raise awareness of interdisciplinary e-journal titles (Enoch \& Harker, 2015) and engage in conversations about e-resource access and pricing trends (Dawson, 2015).

Rogers and Wesley's 2015 article, "Reaching New Horizons: Gathering the Resources Librarians Need to Make Hard Decisions," discusses using soft skills to successfully implement decisions that disrupt the status quo. Rogers and Wesley summarize a lecture by J. P. Rogers, a librarian who made the controversial decision not to renew the American Chemical Society online journal package at The State University of New York at Potsdam. Rogers' lecture detailed the skills, resources, and strategies that lay the groundwork for the cancellation. Rogers advised librarians, "Plant your flag in the values you've identified, and use them to scaffold your actions and your presence in your community and to build your credibility" (Rogers \& Wesley, 2015, p. 70). Further, Rogers emphasized the importance of cultivating an authoritative and trust-worthy reputation and developing strong professional relationships built on good communication as a foundation for implementing change.

The importance of good communication is the prevailing theme of Emery and Stone's 2013 article, "Cancellation and Replacement Review." Emery and Stone suggested strategies for working with faculty before cancellation, and for communicating with users and vendors after decisions have been made. For users, Emery and Stone recommended focusing on any positive aspects of the changes and giving enough notice so that saved lists and other data can be transferred. Chilton and Zhao (2012) noted that offering three month's notice before making decisions is appreciated. For vendors, Emery and Stone advocated being honest about the reasons for cancellation. Emery and Stone also reminded librarians that 
working relationships extend into the future if post-cancellation access is available, as when perpetual access to the backfiles or the content from previously subscribed years is maintained. Good communication between collection librarians and stakeholders may not change the outcome of cancellation decisions, but it creates a more positive environment moving forward.

Since librarians are less likely to publish articles describing the negative impacts of their cancellation decisions, it is difficult to ascertain the impacts libraries have experienced after cancelling Big Deals. Jones et al. (2013) expressed a significant negative impact on content access following the cancellation of Springer and Wiley-Blackwell Big Deals. Nabe and Fowler (2015), however, considered their Big Deal cancellations a success, as they resulted in significant cost savings and stable budgets without undue hardship for library users.

\section{Alternatives to the Big Deal}

Options are increasing for providing just-in-time content at lower costs. When considering Big Deal cancellations, or in their aftermath, it is worthwhile for librarians to examine various models for e-resource provision. Enoch and Harker (2015) cited Pay-Per-View (PPV), Copyright Clearance Center's Get it Now service, and interlibrary loan (ILL) as alternatives to their Big Deals. In addition to Copyright Clearance Center's Get it Now service, Bosch and Henderson (2015) listed DeepDyve and ReadCube as additional examples of individual article access services.

Fought (2014) described the Pay-Per-View (PPV) model as a "viable alternative to the traditional journal subscription model" (p. 195). In a pilot project at a small health sciences library, Fought found that the PPV model generated a higher number of downloads from a greater number of journals, while remaining budget-neutral. Fears of misuse, such as systematic downloads or accessing articles already available in print, were not realized, but Fought cautioned larger institutions to examine their own risks carefully (p. 195). Brenneise (2015) outlined some advantages and disadvantages of renting articles and bulk purchase. Advantages included users' ability to vet article contents before purchase and discounted prices due to bulk purchasing. Disadvantages involved content limitations, content changes, printing restricting, and possible abuse of the service.

The University of Utah Marriott Library partnered with Labtiva, Inc. to pilot a Demand Driven Access (DDA) service using ReadCube software (England \& Jones, 2014). When installed on users' computers, ReadCube Access allowed researchers to view articles at a lower cost than PPV or purchase. The library offered two tiers of access: a 48-hour rental (billing the library $\$ 2.99$ per article) or unlimited cloud access for $\$ 7.99$ per article. Neither option allowed for printing or sharing. The results of the pilot revealed that ReadCube Access was more economical than both ILL and subscriptions for high cost, low-use titles. Users appreciated the easy-to-use interface and immediate access, but they desired access to broader content, search options beyond Google Scholar and PubMed, and the option to print and share content (England \& Jones, 2014).

A recurring theme in the literature about e-journal cancellations is Interlibrary Loan (ILL). There are two primary concerns: the impact of 
cancellations on ILL demand and the cost comparison of ILL service to other methods of providing journal content. England and Jones (2014) determined that ILL is cost effective for titles with low demand, but that cost per use rises significantly as demand for a title increases. Leon and Kress determined the average cost of ILL at $\$ 7.93$ per article (as cited in England \& Jones, 2014, p. 102). Pedersen, Arcand, and Forbis (2014) used an average cost of $\$ 17.50$ per article, derived from the Association of Research Libraries' 2012 ILL cost study, as a threshold for acceptable cost per use. Pedersen et al. also used ILL data to inform selection of new journal titles. Knowlton, Kristanciuk, and Jabaily (2015) posited that compared to the cost of an e-journal subscription, any increase in ILL costs is unlikely to exceed the subscription cost.

Many researchers expected that cancellations would cause a corresponding spike in ILL demand (Knowlton et al., 2015; Pedersen et al., 2014). On the contrary, studies demonstrated no correlation between cancellations and an increase in ILL demand (Knowlton et al., 2015). In fact, Pedersen et al. (2014) found a decline in ILL usage continued even after cancelling a Springer Big Deal. Nabe and Fowler's (2015) analysis of ILL data also showed that the demand indicated by download statistics does not translate into ILL requests after cancellation. Nabe and Fowler termed this "authentic demand" (p. 21): that usage statistics are deceptive, since the demand does not carry over into ILL requests. Knowlton et al. (2015) presented a more nuanced perspective by using web analytics to study user behavior, determining that for every ILL request, there are at least two articles of interest that patrons have chosen not to pursue. They suggested that ILL is not an effective alternative to journal subscriptions (Knowlton et al., 2015).

\section{Conclusion}

There is no one-size-fits-all approach to the evaluation of e-journal subscriptions. Many factors can be used to determine usefulness and quality, including usage statistics, overlap analysis, and input from subject specialists. Various strategies can help guide the decision-making process and assist in the aggregation of data to draw meaningful conclusions. The decision grid is the most popular approach. When libraries make the decision to cancel Big Deal subscriptions, communication is an important factor in creating a positive outcome. Involving stakeholders in the decision-making process and communicating openly with both users and vendors improves the end result.

The e-journal landscape is complex and includes many models of access to meet the needs of users. Big Deals continue to be a widely used approach for obtaining broad access, but recent trends point to dwindling support as costs climb and budgets fall. Individual, or à la carte, title subscriptions are one of many other options currently available, including rental and cloud access models that trade lower cost for restricted use. Despite arguments that it cannot replace access to content lost through cancellations, ILL remains an important support service to supplement library holdings.

Rapidly changing technologies have enabled a transformation in serials delivery models. Since the advent of electronic access, changes appear to be largely reactionary: when the current model becomes untenable, stakeholders react, resulting in new directions. It is an interesting time to be involved with e-journals. 
Research in this area will certainly continue; future directions could further explore the impacts of e-journal cancellations on users, the effects of increasing open access content, and address the advantages and disadvantages of various delivery models with the perspective of longer-term hindsight.

\section{References}

Banks, R. A. (2006). Decision-making factors related to bibliographic database cancellation. Behavioral \& Social Sciences Librarian, 25(1), 93-110. doi:10.1300/J103v25n01_04

Bergstrom, T. C., Courant, P. N., McAfee, R. P., \& Williams, M. A. (2014). Evaluating big deal journal bundles. Proceedings of the National Academy of Sciences, 111, 9425-9430. doi:10.1073/pnas.1403006111

Blackburn, J., McFarland, D., \& Reed, K. (2013, July). Culling the herd in hard times: Implementing an evidence-based "Big Deal" cancellation support tool at Vancouver Island University Library. Poster session presented at the $7^{\text {th }}$ International Evidence Based Library and Information Practice Conference, Saskatoon, Saskatchewan. Retrieved from http://eblip7.library.usask.ca/docs/EBLIP7\%20\%20Big\%20Deal\%20Assessment\%20Tool\%20PosterReed

Bosch, S., \& Henderson, K. (2015). Whole lotta shakin' goin' on. Library Journal, 140(7), 30-35.

Brenneise, P. (2015). Renting articles and buying in bulk. Information Today, 32(3), 18.

Bucknall, T., Bernhardt, B., \& Johnson, A. (2014). Using cost per use to assess Big Deals. Serials Review, 40, 194-196. doi: $10.1080 / 00987913.2014 .949398$

Bucknell, T. (2012). Garbage in, gospel out: Twelve reasons why librarians should not accept cost-per-download figures at face value. The Serials Librarian, 63, 192-212. doi:10.1080/0361526X.2012.680687

Chilton, G., \& Zhao, C. (2012). Thriving in the e-resource amusement park: Using the ADDIE instructional design model as a management framework. Brick and Click Libraries: An Academic Library Symposium, 21-29.

Retrieved from http://eric.ed.gov/?id=ED537605

COUNTER. (2016). What is COUNTER? Retrieved from https://www.projectcounter.org/code-of-practice/faqs/

Dawson, D. (2015). A triangulation method to dismantling a disciplinary "Big Deal." Issues in Science \& Technology Librarianship, Spring(80). doi: $10.5062 / \mathrm{F} 4610 \mathrm{X} 9 \mathrm{H}$

Emery, J., \& Stone, G. (2013). Cancellation and replacement review. Library Technology Reports, 49(2), 35-38.

England, M., \& Jones, P. (2014). Diversification of access pathways and the role of demand-driven acquisition: A case study at the University of Utah. The Serials Librarian, 66, 96-105. doi:10.1080/0361526X.2014.879012

Enoch, T., \& Harker, K. R. (2015). Planning for the budget-ocalypse: The evolution of a serials/ER cancellation methodology. The Serials Librarian, 68, 282-289. doi:10.1080/0361526X.2015.1025657 
Foudy, G., \& McManus, A. (2005). Using a decision grid process to build consensus in electronic resources cancellation decisions. Journal of Academic Librarianship, 31, 533-538. doi:10.1016/j.acalib.2005.08.005

Fought, R. L. (2014). Breaking inertia: Increasing access to journals during a period of declining budgets: A case study. Journal of the Medical Library Association, 102, 192-196. doi:10.3163/1536-5050.102.3.009

Frazier, K. (2001). The librarians' dilemma: Contemplating the costs of the "Big Deal." D-Lib Magazine, 7(3). doi:10.1045/march2001-frazier

Frazier, K. (2005). What's the Big Deal? The Serials Librarian, 48, 49-59. doi:10.1300/J123v48n01_06

Jones, M. A., Marshall, D., \& Purtee, S. A. (2013). "Big Deal” deconstruction. The Serials Librarian, 64, 137-140. doi:10.1080/0361526X.2013.760389

Juznic, P. (2009). Using a decision grid process to evaluate library collections and e- journals. New Library World, 110, 341-356. doi: $10.1108 / 03074800910975160$

Knowlton, S. S., Kristanciuk, L. K., \& Jabaily, M. J. (2015). Spilling out of the funnel. Library Resources \& Technical Services, 59, 4-12.

Nabe, J., \& Fowler, D. C. (2015). Leaving the "Big Deal" ... five years later. The Serials Librarian, 69, 20-28. doi:10.1080/0361526X.2015.1048037

Pedersen, W. A., Arcand, J., \& Forbis, M. (2014). The Big Deal, interlibrary loan, and building the user-centered journal collection: A case study. Serials Review, 40, 242-250. doi:10.1080/00987913.2014.975650

Poynder, R. (2011). The Big Deal: Not price but cost. Information Today, 28(8). Retrieved from http://www.infotoday.com/IT/default.asp

Rogers, J. P., \& Wesley, K. (2015). Reaching new horizons: Gathering the resources librarians need to make hard decisions. Serials Librarian, 68, 6477. doi: 10.1080/0361526X.2015.1016831

Schoen, D., Gammon, J., Rolnik, Z., Schatz, B., Lowe, E., \& Packer, D. (2006). Serials industry: Truth or dare. Serials Librarian, 50, 137-145. doi:10.1300/J123v50n01_13

Schöpfel, J., \& Leduc, C. (2012). Big deal and long tail: A case study on e-journal usage and subscriptions. Library Review, 61, 497-510. doi:10.1108/00242531211288245

Suseela, V. J. (2011). Application of usage statistics for assessing the use of ejournals in University of Hyderabad: A case study. The Electronic Library, 29, 751-761. doi:10.1108/02640471111187980

Sutton, S. (2013). A model for electronic resources value assessment. The Serials Librarian, 64, 245-253. doi:10.1080/0361526X.2013.760417

Tenopir, C. (2009, October). Measuring the value and return on investment of academic libraries. In D. Pental (Chair), Globalizing Academic Libraries: Vision 2020. Proceedings of the International Conference on Academic Libraries 2009, Delhi University Library System, Delhi. Retrieved from http://crl.du.ac.in/ical09/papers/index_files/ical-2_158_377_1_RV.pdf

Trail, M. A., Chang-FitzGibbon, K., \& Wishnetsky, S. (2012). Using assessment to make difficult choices in cutting periodicals. The Serials Librarian, 62, 159-163. doi:10.1080/0361526X.2012.652931 